\title{
A Promising Alternative to Temporal Artery Biopsy for GCA
}

\section{Sandhu $\mathrm{Z}^{1 *}$, Shaikh $\mathrm{S}^{2}$ and Reardon $\mathrm{M}^{3}$}

${ }^{1}$ AMAU Staff Physician, Wexford General Hospital, Ireland

${ }^{2}$ Staff Physician, General Medicine, Wexford General Hospital, Ireland

${ }^{3}$ Associate Professor, Consultant Geriatrician, Wexford General Hospital, Ireland

${ }^{\star}$ Corresponding author: Zulfiqar Ali Sandhu, Staff Physician, AMAU, Wexford General Hospital, Ireland; Email: Zulfiqar.Sandhu@hse.ie

Received: June 15, 2020; Accepted: June 22, 2020; Published: June 29, 2020

\section{Case Report}

A 57 year old gentleman was referred by GP to our Acute Medical Assessment Unit with right sided headache. He described 3 days history of right fronto-parietal headache with "heaviness" and associated blurring of vision and dizziness. The headache was paroxysmal 'coming in waves" and did not respond to first line analgesics. He is an exsmoker, living on his own with no past medical history of note.

On examination, he had right sided temporal tenderness without any other findings. CNS exam was unremarkable. There was no evidence of proximal muscle weakness.

His laboratory investigations including inflammatory markers were within normal limits. A working diagnosis of Temporal Arteritis was made and he was commenced on High dose oral Steroids with bone protection and PPI. Temporal artery biopsy was performed which did not show any evidence of vasculitis. Ultrasound of Temporal Artery was organised which showed hyperechoic thickening of Right temporal artery, highly suggestive of Temporal Arteritis, thus confirming the clinical suspicion (Figure 1). He was discharged on tapering dose of steroids, PPI and bone protection and was reviewed periodically in clinic. He is clinically asymptomatic on treatment.

\section{Discussion}

Giant Cell Arteritis is the most common systemic vasculitis and the vascular involvement can be widespread [1]. It is common in older white males after age of 50 years with peak incidence after the age of 70 [2].

The presentation can be acute or subacute with symptoms of low grade fever, headache, jaw claudication, visual problem and constitutional symptoms. Temporal arteritis can lead to transient or permanent visual loss. There is an association between temporal arteritis and Polymyalgia Rheumatica [3].

Temporal Arteritis poses a diagnostic challenge and traditionally the diagnostic criteria used, incorporates clinical presentation, inflammatory markers and temporal artery biopsy. Temporal Artery biopsy is used to acquire the evidence of vasculitis, however it can be normal due to the presence of skip lesions [4]. The segmental nature of arteritis leads to high false negative results of biopsy and hence the

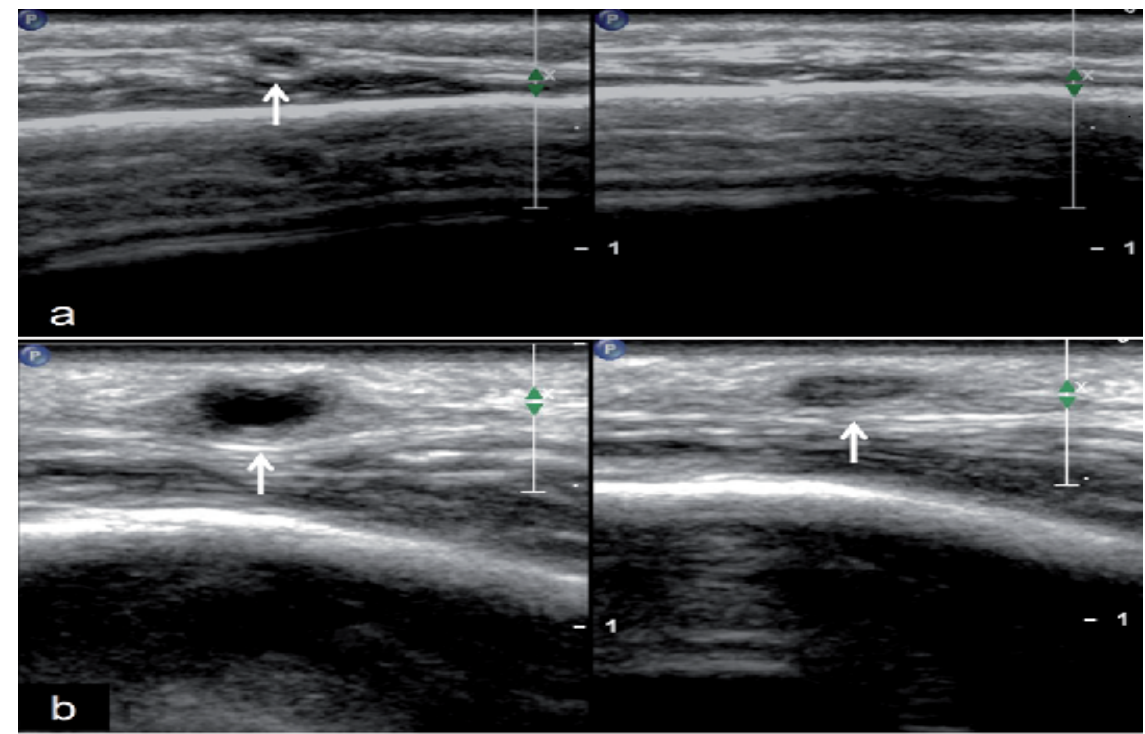

Figure 1: (a) Loss of temporal artery visibility on compression of artery. (b) Temporal artery wall maintained despite compression ('compression sign'). 
sensitivity of biopsy has never been calculated. The negative biopsy results can be as high as $30-40 \%$ [5].

Colour Doppler Ultrasonography has emerged as an alternative to Temporal Artery biopsy. The two signs explained in the literature are the presence of "halo" sign (representing mural oedema) and the presence of 'compression sign' (representing persistent halo after compressing artery with ultrasound probe) [6]. Albert et al. (2007) in a retrospective analysis postulated that ultrasonography has superseded temporal artery biopsy and should be reserved for situations where the imaging is inconsistent with the clinical picture [7].

High dose glucocorticoids remain the mainstay of therapy and should be commenced as soon as the diagnosis is suspected [8]. Steroid sparing agents such as Tocilizumab and Methotrexate can be used in patients who develop complications and intolerance to steroids [9]. Bone and gastric protection along with antiplatelets and Rheumatology follow up is advisable.

\section{Conclusion}

Temporal Arteritis is a debilitating form of vasculitis if left untreated. It remains a diagnostic challenge especially due to the nature of vascular involvement. Temporal biopsy can be falsely negative; colour doppler ultrasonography is emerging as a new diagnostic tool in suitable patients. The ultrasonography is non-invasive and is readily available.

\section{References}

1. Gonzalez-Gay MA, Vazquez-Rodriguez TR, Lopez-Diaz MJ, et al. (2009) Epidemiology of giant cell arteritis and polymyalgia rheumatica. Arthritis Rheum 61: 1454. [crossref]

2. Crowson CS, Matteson EL, Myasoedova E, Michet CJ, Ernste FC, et al. (2009) The lifetime risk of adult-onset rheumatoid arthritis and other inflammatory autoimmune rheumatic diseases. Arthritis Rheum 63: 633. [crossref]

3. Jones JG (1991) Clinical features of giant cell arteritis. Baillieres Clin Rheumatol 5: 413. [crossref]

4. Duhaut P, Pinède L, Bornet H, Demolombe-Ragué S, Dumontet C, et al. (1999) Biopsy proven and biopsy negative temporal arteritis: differences in clinical spectrum at the onset of the disease. Groupe de Recherche sur l'Artérite à Cellules Géantes. Ann Rheum Dis 58: 335. [crossref]

5. Ashton-Key MR, Gallagher PJ (1992) False-negative temporal artery biopsy. Am J Surg Pathol 16: 634. [crossref]

6. Schmidt WA, Kraft HE, Vorpahl K, Völker L, Gromnica-Ihle EJ (1997) Color duplex ultrasonography in the diagnosis of temporal arteritis. N Engl J Med 337: 1336. [crossref]

7. Alberts MS, Mosen DM (2007) Diagnosing temporal arteritis: duplex vs. biopsy. QJM 100: 785. [crossref]

8. Proven A, Gabriel SE, Orces C, et al. (2003) Glucocorticoid therapy in giant cell arteritis: duration and adverse outcomes. Arthritis Rheum 49: CXS703.

9. Stone JH, Tuckwell K, Dimonaco S (2017) Trial of tocilizumab in giant-cell arteritis. N Engl J Med 377: 317. [crossref] 